third. The region was chosen as second in importance by North America, but not among the top three priorities of Europeans. As occurred in the former IAU survey, this part of the world was not chosen as a first priority by any region, including itself. This reflects earlier findings, which is more focused on North America and Europe than on its own region and the rest of the world.

The highest priority for the internationalization of the curriculum is language learning, a logical consequence of the deficiency in this area. Latin America and the Caribbean also appears as the region with the smallest number of joint and double-degree programs. Although this is a modality in full growth around the world, just 29 percent of these institutions report having joint degree arrangements, and 34 percent double-degree programs, in contrast to the world average of 4I percent and 44 percent, respectively. Noteworthy are the region's insufficient strategies for recruiting international students and scholars, resulting in one of the world's smallest percentage of international students and scholars.

This region is reported with the smallest percentage of institutions having internationalization policies in place $(6 \%$ lower than the world average); and, consequently, it has the highest percentage of institutions currently preparing internationalization policies/strategies $(6 \%$ higher than the world average). This confirms a growing awareness that efforts should be made toward this end. The region also reports having the least institutionalized and professionalized international offices, something in line with other studies, such as the 20II report on international cooperation between the European Union and Mexico. This situation might limit the potential and viability of internationalization strategies.

These highlighted findings definitely show a positive trend in Latin America and the Caribbean internationalization processes. Progress has been achieved in student and faculty mobility. Large-scale scholarship programs for international postgraduate studies and networking for scholars are top priorities. Language learning, after being reported for years as one of the main barriers, has become a top priority. Governments have increased support and funding, and institutions are in the process of improving or creating their organizational structures for internationalization.

Nevertheless, if compared with other developing regions, Asia or even Africa, the region is still lagging behind in terms of financial support, student, and faculty mobility, curriculum internationalization, organizational structures, and staff professionalization. But our main concern for the future is that efforts are mainly focused on individual strategies (mobility) and not enough on systemic strategies (curriculum, research and faculty profiles. Without denying the positive and transformative value of such actions, they have nevertheless been proved not to be sufficient to make a decisive contribution to the sector's transformation. This could suggest a lack of conceptualization from decision makers of the transformative potential of comprehensive internationalization, in terms of innovation, quality, and relevance. Furthermore, an important handicap to internationalization might also lie in the political culture and management styles both at the institutional and sector level. Here, short-term strategies and actions are generally privileged, whereas internationalization requires mediumand long-term planning. In addition, other areas-such as increasing access, equity, quality, relevance, and knowledge production-are also in urgent need of support at all levels.

\section{Institutional Engagement in Internationalization of Higher Education: Perspec- tives from Kazakhstan}

\section{Aisti Li ANd Adil Ashirbekov}

Aisi $L i$ is a postdoctoral researcher at the Graduate School of Education, Nazarbayev University, Astana, Kazakhstan. E-mail: li.aisi@ nu.edu.kz. Adil Ashirbekov is a junior researcher at the same school. E-mail: aashirbekov@nu.edu.kz.

T nternationalization has become increasingly important in 1 national and institutional higher education development strategies. Kazakhstan is no exception: since the I990s, the country has entered a period of reform, with internationalization representing a vital component of this process. In 20I0, Kazakhstan became a full member of the Bologna process, signaling a new phase of the internationalization of its higher education system. These new developments, initiated from the top, were not necessarily received at the institutional level with open arms. Various challenges have emerged in the past few years, ranging from the lack of capacity at individual institutions to the disjunction of strategies at the national and institutional levels.

In order to generate insight into the level of engagement of individual institutions with the internationalization of higher education in Kazakhstan, Nazarbayev University Graduate School of Education is conducting a three-year research project, funded by the Ministry of Education and Science of the Republic of Kazakhstan. Although the project is only in its first year, the initial findings are indicative of several key issues for internationalizing Kazakhstan's higher education sector. 


\section{QuAntity Over Quality}

Reforms invite results-yet, how to measure the results is often not clear. Similarly, how to assess the degree of internationalization and its success (or failure) poses a difficult question. It is not surprising that Kazakhstani policymakers and institutional leaderships have opted for statistically quantifying the results of internationalization, since statistics are assumed to provide solid answers when it comes to auditing.

Student and faculty mobility lies at the center of Kazakhstan's internationalization strategy, with a national target of 20 percent of students being mobile by 2020 , as articulated in the Strategy for Academic Mobility in the Republic of Kazakhstan for 2012-2020 and financially supported by the country's Academic Mobility Scholarships. However, in reality, different parties can interpret mobility differently. As pointed out by a senior university leader, going abroad is often associated with sightseeing, not with acquiring knowledge and skills. Furthermore, it was previously discovered that some universities used the government funding to send students abroad merely for language courses or campus visits, just to fulfill the ministerial quota for student mobility. The Kazakhstani government has learned a lesson from this and subsequently created the Center for

\section{Student and faculty mobility lies at the center of Kazakhstan's internationaliza- tion strategy, with a national target of 20 percent of students being mobile by 2020.}

International Programs for monitoring and quality control of these scholarships.

In addition, the majority of survey respondents from the international offices cited the number of international partnerships and foreign faculty members as successful examples of internationalization at their institutions. However, our interviews with university rectors showed that not all international agreements were executed, and many of them fell dormant with the absence of an explicit road map. Impressive as some of the figures may seem, the actual impact of these factors remains unknown.

\section{To Centralize or Not to Centralize}

In Kazakhstan, the pressure to internationalize comes from the top. During our interviews, university leaders complain about the constraints imposed by the government on practices of internationalization, ranging from centralized budgets, centralized time frames, to centralized aims. They blame poor cooperation with the ministry for obstructing international projects, as well as the lack of autonomy. Paradoxically, these same leaders calling for more autonomy also criticize the government for not providing sufficient step-by-step guidance for the implementation of internationalization strategies. Thus, while asking for autonomy from the government, at the same time higher education institutions habitually look to the top for comprehensive regulation and direction.

\section{Shortage of Qualified Professionals}

Closely related to the dependence on governmental guidance is the lack of qualified internationalization professionals in higher education institutions. Our research shows that while most universities have offices dedicated to internationalization, some lack professionals specializing in international activities, and some universities' international offices do not possess the necessary skills to initiate or sustain international cooperation. Even common activities, vital to fulfilling their core role, such as writing formal business e-mail in English, present obstacles for many international offices. It is evident that more training opportunities, domestically or internationally, are needed for staff in the international offices.

There are highly qualified professionals in the Kazakhstani employment market. However, as pointed out by the respondents in our study, higher education institutions often lose out in the fierce competition against other sectors. Regional institutions face an even more dire situation when it comes to human resources. One respondent mentioned that regional institutions do not provide academic programs related to internationalization (e.g., international relations), thereby further restricting the supply of qualified professionals in the local job market. Combined with the fact that young people tend to seek employment in metropolitan areas, such as Astana and Almaty, regional institutions are severely disadvantaged in recruiting qualified candidates able to promote internationalization.

\section{Distance Matters}

Distance matters when it comes to international partnerships, at least in the case of Kazakhstan. Our study shows that there is a disjunction of internationalization strategies between the governmental and institutional levels. The government expressly leans toward the broader Europe, as reflected in Kazakhstan's participation in the Bologna process. Although university leaders indicated to us that they would ideally prefer to partner with European or American institutions, they also note that the current reality is that student and faculty mobility, as well as cross-border part 
nerships, is strongly concentrated on Russia, other postSoviet countries, and neighboring countries.

At the same time, Kazakhstan's universities are aware of their comparative advantage in higher education provision among Central Asian countries. The respondents in our study mentioned that the recruitment of foreign students should not exclusively focus on European countries. Instead, more attention should be paid to attract more students from neighboring countries. Whether this institutional demand fits into the national strategy, and thus gains support from the government, remains to be seen.

\section{The Language Gap}

Language can also create a sense of distance: poor proficiency in foreign languages, particularly in English, is reported to be another major barrier to internationalization. Participants in our study frequently cite this as an obstacle at various levels: for instance, student and faculty mobility, research collaboration, and international office operations. This also extends to the lack of availability of Englishlanguage programs in Kazakhstani institutions, as well as qualified teaching staff. In comparison, respondents who report excelling in foreign languages see this as a strength for developing international partnerships. The rectors of those institutions lagging behind in foreign languages say that they are investing in improving language proficiency as an important step toward internationalization.

\section{Open Dialogue and Cooperation}

The above factors certainly do not cover every aspect of the process of internationalization of higher education in Kazakhstan, and further research in our project will look into these. Even so, one can see key areas of potential challenges that the Kazakhstani government and higher education institutions face. In the first place, there is a wide gap between Kazakhstan and more developed countries in terms of internationalization. Secondly, there is also a gap developing within the country between institutions, particularly between metropolitan and regional ones. The Kazakhstani government has demonstrated its ambition to internationalize its higher education institutions, as evidenced by its policies and financial support. Higher education institutions are also actively participating in the process. However, there needs to be a more open dialogue and closer cooperation between the government and institutions to align their visions and construct effective support mechanisms, in order to make further progress in internationalization.

\section{Internationalization of} Japanese Universities: Learning from the CAMPUS Asia Experience

\section{MIKI HorIE}

Miki Horie, PhD is associate professor at Ritsumeikan International, Ritsumeikan University, Japan. She was a visiting scholar at CHEI in Milan in the fall of 2013. E-mail: mhorie@fc.ritsumei.ac.jp.

$\mathrm{W}$ hat has internationalization brought to Japanese higher education institutions? Japanese universities experience various reforms and self-improvement processes as responses to the internationalization policies initiated by the Japanese government since I980s. The major focus of the government before 2000 was to increase the number of international students, and from then it started to undertake multidimensional approaches to internationalization, including promotion of outbound and multilateral mobility, development of English-taught programs, and collective efforts for international student recruitment. Universities responded to requirements and expectations in various ways within the frameworks that come with the government's financial support. Through such efforts, Japanese universities have accumulated collective experience and knowledge.

One significant outcome is the increased awareness of the need to apply alternative pedagogical models—such as, experiential, active, and collaborative learning schemeswhich serve students more efficiently and effectively in cross-cultural learning environments. One of the examples is the policy called CAMPUS Asia, or "Collective Action for Mobility Program of University Students in Asia," which challenges Japanese universities to develop joint programs with Chinese and Korean counterparts for mutual understanding. This is the first joint governmental initiative between Japan, China, and Korea, to educate their youth together. The three governments jointly selected ten project proposals-in other words, ten consortia of Japanese, Chinese, and Korean universities—as grant recipients.

\section{The "East Asian Leaders" Program}

After one year of implementation, the government committee responsible for the interim evaluation of CAMPUS Asia gave the highest grade to one program among the Io selected, the "East Asian Leaders" program operated by Ritsumeikan University (Japan), Guangdong University of Foreign Studies (China), and Dongseo University (Korea). Besides the interim evaluation, another sign of success lies in the fact that the participants of the program have started 